\title{
Honey bees (Hymenoptera: Apidae) outnumber native bees in Tasmanian apple orchards: Perspectives for balancing crop production and native bee conservation
}

\author{
Kit S Prendergast, ${ }^{1 *}$ (D) Nicolas Leclercq ${ }^{2}$ (D) and Nicolas J Vereecken ${ }^{2}$ (D) \\ ${ }^{1}$ Molecular and Life Sciences, Curtin University, Bentley, WA 6102, Australia. \\ ${ }^{2}$ Agroecology Lab, Free University of Brussels, Boulevard du Triomphe CP 264/02, Brussels B-1050, Belgium.
}

\begin{abstract}
Apples are a major crop globally, including in Tasmania (Australia) - known as 'the Apple Isle' owing to the key role of apples in Tasmania's history and economy. Most apple cultivars are obligate entomophilous species, and fruit quantity, quality and economic value are enhanced under insect pollination. Whilst the introduced European honey bee (Apis mellifera) is often assumed to be the main pollinator of apple in most regions of the world, including Australia, there is an increasing interest in alternative pollinators. The pollinator community of Tasmanian apple crops, however, has never been assessed. In this study, we surveyed four apple orchards for 3 days each during peak bloom in the Huon Valley region to characterise bee assemblages visiting blooming apple trees and the native bee fauna associated with surrounding flowering vegetation. Our results show that honey bees were the predominant visitors to apple blossoms ( $90.7 \%$ of visits), followed by the introduced bumble bee Bombus terrestris ( $5.9 \%$ of visits), with only a minor contribution by native bees ( $3.3 \%$ of visits). Twenty-six species of native bees were collected in total, of which only 10 species (five Exoneura (Apidae), four Lasioglossum (Halictidae) and one Euryglossa (Colletidae) species) were collected from apple blossoms, with Exoneura being the most abundant visitors. Few native bees were captured on apple blossoms, however co-blooming surrounding native vegetation, as well exotic flowers, hosted a high diversity and abundance of native bees. Site conditions influenced community composition, including abundance and representation of introduced bees compared to native bees visiting apples. Additionally, warmer temperatures favoured native bees. Collectively, our results suggest that Tasmania's apple production in its current state is unlikely to rely exclusively on native pollinators. Native bees nevertheless warrant conservation in such an insular crop production system. This can be achievable through retaining native flowering plants and even exotic non-crop flowers in and around orchards. Promoting the diversity and abundance of native bees through habitat enhancement may have additional benefits, such as filling current and future pollination demands and gaps, a key strategy under scenarios of climate change.
\end{abstract}

Key words apple, bee, bumblebee, honey bee, native bee, Tasmania, weather, weed, wild bee, wildflower.

\section{INTRODUCTION}

Apples (Malus domestica varieties: Rosaceae) are a major food crop across the world, including in Australia where it has been introduced by colonists and cultivated since the late 17 th century (Luby 2003; Keogh et al. 2010a). The majority of apple cultivars are self-incompatible (Dulta \& Verma 1987), produce seeds through obligate entomophily, and insect pollination is reported to enhance yield, fruit quality and overall crop economic value (Klein et al. 2007; Garratt et al. 2014; Miñarro \& García 2018; Pardo \& Borges 2020). Honey bees (Apis spp., predominantly Apis mellifera, but also Apis cerana in southern, south-eastern and eastern Asia) are traditionally used as the main pollinators of apples (Pardo \& Borges 2020), yet there is increasing interest in alternative pollinators, including in Australia, owing to the similar or higher per-visit performance in pollen transfer by native or other managed species (Hogendoorn et al. 2006; Rader et al. 2009; Mader et al. 2010; Christmann \& Aw-Hassan 2012).

*kit.prendergast21@gmail.com
Although honey bees are usually considered to be the most important pollinator of apple flowers, there is evidence to suggest that solitary native bees have proven as effective, if not more effective, than honey bees as pollinators of apple flowers (Vicens \& Bosch 2000; Bosch \& Kemp 2002; Mallinger \& Gratton 2015; Park et al. 2016). This is due to comparatively low pollination efficiency at the individual level in honey bees because they move between flowers on the same plant or because the pollen they collect is no longer available for plant sexual reproduction, making them poor pollinators for plants such as self-incompatible apple varieties (Free 1966). Honey bees may even be detrimental to successful pollination as they have been observed to primarily visit petal-less or even wilted flowers with dehiscing anthers (Williams \& Brain 1985). In addition, pollinator diversity has been found to positively affect apple yield (Martins et al. 2015; Blitzer et al. 2016; Földesi et al. 2016), and more generally, reports indicate that diverse wild bee communities are of overarching importance for effective pollination and inter-annual yield stability for many crops (Garibaldi et al. 2011; Garibaldi et al. 2013), particularly in a context of global change 
(Potts et al. 2010; Potts et al. 2016; Settele et al. 2016). Differences in body size and thermal niche may mean that different bee taxa are differentially affected by weather and climatic conditions (Buckley \& Kingsolver 2012), and so an understanding of how temperate-origin introduced bees, and the endemic Australian bees, respond to variations in temperature and other environmental conditions can provide more stable pollination services (Tuell \& Isaacs 2010) and help predict how pollination assemblages may be influenced by variable weather conditions, as well as ongoing climate change (Grose et al. 2010; Rader et al. 2013).

It is estimated in Australia that apple yield would decline by $90 \%$ in the absence of honey bees (Gibbs \& Muirhead 1998). However, Australia has a rich diversity of native bees, comprising over 2000 species, including pollen generalist taxa (Houston 2018), with the potential to forage on apple flowers. Despite the economic importance of the crop pollination services, management guidelines for pollination to focus primarily on honey bee management (Goodman 1994; Department of Primary Industries and Regional Development 2017). To date, the few studies documenting the bee visitors to apple flowers in Australia have been limited to coarse taxonomic levels (Saunders \& Luck 2016; Brown et al. 2020). Furthermore, in a recent study by Saunders and Luck (2018), honey bees were excluded on the assumption that they were managed, which may be inappropriate given that feral honey bees are often present in Australian ecosystems (Paton 1996) and which has hindered the possibility to properly evaluate the relative contribution of honey bees to crop pollination. Another introduced pollinator species of interest in the Tasmanian context besides the European honey bee is the bumblebee Bombus terrestris, which was first recorded in Tasmania in 1992 as an illegally introduced species. Today, $B$. terrestris is well established in the Apple Isle and occupies much of the territory (Semmens et al. 1993; Hingston 2006). Although known to be effective pollinators of apple flowers (Goodell \& Thomson 1997; Thomson \& Goodell 2001; Pérez-Méndez et al. 2020), bumblebees have potential negative impacts on both native bees and honey bees through competition (Kingston \& Mcquillan 1998; McQuillan \& Hingston 1999) and can promote the spread of invasive weeds (Stout et al. 2002).

Insular landscapes are theoretically expected to be characterised by a depauperate fauna compared to the neighbouring continent (Michener 1979), but the extent to which the 'Apple Isle' of Australia (McConnell \& Servant 1999; Hall 2014) harbours diverse communities of native bees and what flora they rely on (apples as well as alternative foraging resources) remains virtually unknown. This is however particularly relevant to the economy of the Tasmanian pome fruit industry, which is dominated by apple production, has a farm-gate value of AUD\$32.2M (Fruit Growers Tasmania 2019) and, in 2002, accounted for approximately $18 \%$ of the total Australian production and 65\% Australian apple exports (Salter 2002).

In this study, we aimed to contribute to filling the above-mentioned gaps in our knowledge by investigating the community structure of bees associated to commercial apple orchards in Tasmania. Specifically, we assessed the contributions of bee taxa - both Australian native bees and introduced bees (honey bees and B. terrestris) as visitors to apple orchards, and identify the native bees visiting the apple flowers as well as other flowering plant species in the vicinity. Results from this study will go towards identifying the importance of different bee taxa to apple pollination in Tasmania and provide management recommendations for enhancing on-farm native bee diversity.

\section{MATERIALS AND METHODS}

\section{Survey methods}

K. S. P. surveyed four apple orchards in October 2019, three of which were 'Certified Organic' (Australian Organic Ltd 2019) and one which used Integrated Pest Management (IPM) (Table S1). Only the IPM orchard had managed honey bee colonies (30 colonies, at densities of approximately 2.5 colonies/ha). Each orchard was surveyed for three consecutive days during the flowering season on days that were suitable for bee activity, namely, when temperatures were $>15^{\circ} \mathrm{C}$, partly cloudy to sunny condition, with wind speeds $<20 \mathrm{~km} / \mathrm{h}$, and no rain.

Orchards were surveyed both passively using bee bowls (also known as pan traps in the literature) (Westphal et al. 2008; Prendergast et al. 2020) and sweep netting with an entomological sweep net. Across all study sites, the same $500 \mathrm{~mL}$ plastic bowls $\left(\mathrm{AVA}^{(B)}\right)$ were used, and they were all painted the same way, first using a primer (white Motip ${ }^{\circledR}$ primer) and then with white, fluorescent yellow and blue spray paints (white and yellow Rocol $^{\circledR}$ paints and fluorescent blue Liquitex ${ }^{(B)}$ paint). Three sets of bee bowls were set out at 9:00 h and collected at 16:00 h ( $7 \mathrm{~h}$ duration). Each set consisted of a triplet of each colour placed $3 \mathrm{~m}$ apart from each other flush on open grassland. Each triplet set was placed at least $30 \mathrm{~m}$ distant. Bowls were half filled with water and unscented liquid soap (1:0.01 water:soap). For $1.5 \mathrm{~h}$ in the morning, and again in the afternoon, K. S. P. slowly traversed the orchard and netted bees from apple blossoms, amounting to a total of $3 \mathrm{~h}$ per survey.

Due to differences in orchard layout, fixed transects were not used, but rather, the sampling effort was standardised by duration. Effort was made to collect all bees observed; although the introduced bees can be identified on the wing, counts were based on collections so as to standardise sampling among the three bee taxa, given that observational counts can greatly exceed numbers of specimens collected (Tangtorwongsakul et al. 2018; Prendergast et al. 2020).

Interspersed between the apple blossom surveys, a total of $3 \mathrm{~h}$ was spent netting native bees from other flowering plants within and surrounding the orchard (within a radius of $50 \mathrm{~m}$ from the border of the apple orchard). Thus, each orchard and the surrounding vegetation were surveyed for a total of $6 \mathrm{~h} /$ day, totalling $18 \mathrm{~h}$ over the 3 days of surveying each orchard. All specimens were stored in labelled jars in ethanol and pinned later in the lab prior to identification. Specimens were identified by K. S. P. using published keys where available (Exley 1976; Walker 1986; Walker 1995; Batley \& Houston 2012), consulting published descriptions (Cockerell 1914, 1918, 1905, 1930) and PaDIL (http://www.padil.gov.au/pollinators/). Native flower 
species were identified using Simmons et al. (2009). Maximum daily temperature was determined from recordings for the region provided by the Bureau of Meteorology (http://www.bom.gov. $\mathrm{au} / \operatorname{tas} /)$.

\section{Statistical analyses}

Statistical analyses were performed in R version 3.6.2 (R Core Team 2019). The effect of predictor variables on response variables was analysed using mixed-effect models (package lme4 (version 1.1-24) (Bates et al. 2015), with orchard included as a random factor to account for repeated visits. For each model, each survey represented an observation $(N=12)$, and netting data from the morning and afternoon period were pooled. The low sample size precluded testing interaction effects. As the response variables - abundance and species richness - were count data, generalised linear mixed-effect (glmer) models with a Poisson distribution were first constructed and checked for overdispersion and normality using the dispersion_glmer function (package blmeco (version 1.4) (Korner-Nievergelt et al. 2015) and qqPlot (resids()) function (Fox 2015). These assumptions were met for models where the response variable was native bee species richness and Bombus abundance. For models where the response variable was honey bee abundance and native bee abundance, these assumptions were not met, and consequently, negative binomial mixed-effect models (glmmTMB function) were used (package glmmTMB (version 1.0.2.1) (Brooks et al. 2017), and residual diagnostics (KS test, dispersion test, outlier test and residual vs. predicted tests) were assessed with the package DHARMa (version 0.3.2.0) (Hartig 2020).

Estimates of the effect size of categorical variables of interest were obtained through a summary output of the model, and for continuous variables, this also indicated the direction of the effect. For categorical variables found to be significant, when the number of levels exceeded two, pairwise contrasts were calculated using Tukey's post hoc tests (lsmeans package (version 2.30-0); Lenth 2016). $R^{2}$ values from glmer models were calculated with the r.squaredGLMM function (package MuMIn (version 1.43.15); Barton 2019) and with the function r2_nakagawa function (package performance (version 0.4.7); Lüdecke et al. 2020) for glmmTMB models.

The significance of explanatory variables was determined using a chi-squared likelihood ratio approach, where an ANOVA was performed between two models with and without the explanatory variable being evaluated, where a chi-squared value corresponding to $P<0.05$ indicated significance.

\section{Effect of temperature}

Temperature was first plotted against sampling date, which revealed that temperature did not vary consistently across the surveys (Fig. S1) and therefore did not confound analyses between orchards. Prior to investigating patterns of visitation between native bees and introduced bees to apple orchards, the effect of temperature was investigated separately for honey bees, bumble bees and native bees.

\section{Differences in visits to apple blossoms between honey bees, bumblebees and native bees}

To determine whether relative abundances of honey bees, bumble bees and native bees in apple orchards differed, we modelled differences in relative abundance between these bee taxa. Separate models were used for bees captured in bee bowls and by sweep netting. A number of specimens (response variable) according to bee taxon (explanatory variable, levels honey bees, bumblebees and native bees) were evaluated using a negative binomial mixed-effect models (glmmTMB function) with orchard site as a random effect to account for repeated visits to each orchard.

\section{Native bees in orchards vs. on surrounding vegetation}

Bees in and around orchards may not necessarily be those visiting the crop blossoms. To investigate this, abundance and species richness of native bees netted on apple blossoms, netted on surrounding non-apple flowers (i.e. native flowers, exotics and weeds) and caught in bee bowls was analysed using mixed-effect models. In addition, to test if there was a 'spillover' of bees present on surrounding flowers to apples, we assessed whether there was an association between native bees on the surrounding vegetation with native bees visiting apple blossoms. This was modelled for both abundance and species richness of native bees, with native bees on non-apple flowers as the predictor variable, and native bees on apple flowers as the response variable, with orchard site as a random effect. Additionally, we visualised the overlap in apples with other flowers for each bee species with a bipartite plant-pollinator interaction network using the R package bipartite (version 2.15) (Dormann et al. 2008).

\section{Associations between introduced bees and native bees}

Introduced species may outcompete native species, resulting in negative associations. This potential for competition between introduced bees (Apis mellifera and Bombus terrestris) with native bees was evaluated by analysing whether introduced bee abundance during a survey influenced native bees present. This was analysed using total abundance of native bees across all methods in relation to total abundance of honey bees and bumblebees recorded (collected on apple blossoms and in the bee bowls) combined, as well as for native bees collected in each location independently (apple blossoms, bee bowls and surrounding flowers). This tested whether introduced bees were excluding native bees from the apple blossoms, as well as at the site scale, respectively.

\section{Turnover among sites}

We assessed beta diversity of native bee assemblages and its partitioning into species replacement (turnover) vs. species richness (nestedness) components using the R package $B A T$ (version 2.4.0) (Cardoso et al. 2015). We calculated total beta diversity, as well as its two components, species replacement and species 
richness effects (Carvalho et al. 2012) based on a species x site matrix with species abundances pooled for all 3 days at each site, and used the Sørensen family of beta diversity.

\section{RESULTS}

Across all surveys combining all collection methods, a total of 1247 honey bees, 81 bumblebees (69 queens and 12 workers) and 358 native bees belonging to 26 species in seven genera and three families were collected (Table 1) (Prendergast 2020b, 2020c).

\section{Differences among bee taxa in apple orchards}

Regarding bees visiting the blossoms of the apple trees, across the 12 surveys, a total of 1236 honey bees were recorded foraging on the apple blossoms, 81 bumble bees and 45 native bees (Table 1). The introduced bees (honey and bumble bees) therefore dominated the bees foraging on apple blossoms, comprising $98.2 \%$ of bees. There were significant differences between numbers of bees foraging on apple blossoms according to bee taxon (i.e. honey bee, bumble bee and native bee) $(P<0.001$; Table 2$)$. On average across all surveys, more honey bees were collected than other taxa (honey bees vs. bumble bees: $P<0.001$; honey bees vs. native bees: $P<0.001$ ), where there were no significant differences between Bombus terrestris and native bees $(P=0.116)$ (Fig. 1a).

In contrast, whilst there were significant differences between taxa in numbers of bees caught in bee bowls $(P<0.001$; Table 2$)$, their relative representation differed from the patterns of bees foraging on the apples: no bumble bees were caught in bee bowls, whereas more native bees than honey bees were caught in the bee bowls $(P=0.002$, Fig. 1b).

\section{Native bees}

The taxonomic composition of native bees in the orchards pooling all collection methods was dominated by species in the family Halictidae (genera Lasioglossum and Homalictus) and in the genus Exoneura (Apidae) - both polylectic taxa displaying varying degrees of sociality (Houston 2018) (Fig. 2a,c-e) (see also Prendergast 2020b, 2020c [Correction added on 11 February 2021, after first online publication: the 'semi-social and polylectic taxa' has been corrected]). Taxa that are more specialised in their pollen foraging preferences were restricted to the orchard A, which had large amounts of native flora in the surroundings (Figs. 2b and 3) (see also Prendergast 2020b). Of the 26 species recorded, only 10 were recorded foraging on apples (Fig. 3) (Prendergast 2020b). These belonged primarily to the genera Exoneura (Apidae, five species) - social species that nest in reeds and hollow stems (Fig. 2a), and Lasioglossum (Halictidae, four species) - semi-social ground-nesting species (e.g. Fig. 2c-e). Only one solitary bee species (Euryglossa sp., Colletidae) was collected foraging on apple blossoms (Fig. 3) (Prendergast 2020c). On average, only one species was recorded foraging on apple blossoms per survey (Table 1), and no species was recorded foraging exclusively on the apple blossoms; however, for five of these species, more individuals were collected on apples than the other flora species (Fig. 3) (Prendergast $2020 \mathrm{~b}$ ). The number of species recorded per survey ranged from 0 to 9 , with an average of $5.5 \pm 0.89$ species collected per survey.

There were significant differences in both abundance and species richness of native bees according to sampling method ( $P=0.003$ and $P<0.001$, respectively) (Fig. 4 and Table 1). There also appeared to be substantial variation in abundance and species richness among orchards (Fig. 4). For both abundance and species richness, more native bees were collected from surrounding flowers than from apple blossoms (abundance: $P=0.006$; species richness: $P<0.001$, whereas bee bowls and

Table 1 Average abundance \pm SE of bee taxa collected on the apple blossoms, in bee bowls, and for native bees, on the surrounding flowers, and overall, and the average species richness of native bees $(N=12)$

\begin{tabular}{lllr}
\hline & Honey bees & Bumblebees & Native bee abundance \\
\hline Apple blossoms & $103 \pm 13.7$ & $6.75 \pm 1.92$ & $3.75 \pm 2.10$ \\
Bee bowls & $0.91 \pm 0.50$ & 0 & $10.91 \pm 5.80$ \\
Surrounding flowers & - & - & $15.17 \pm 3.55$ \\
Overall & 1247 & 81 & 358 \\
\hline
\end{tabular}

Table 2 Differences in abundance among bee taxa (honey bees, bumble bees and native bees) collected foraging on apple blossoms and captured passively in bee bowls in apple orchards

\begin{tabular}{|c|c|c|c|c|c|c|}
\hline Bees netted on apples & Main effect & $\chi^{2}$ & df & $P$ & $R_{\mathrm{m}}^{2}$ & $R^{2} \mathrm{c}$ \\
\hline & Taxon & 58.0 & 2 & $<0.001$ & 0.888 & 0.916 \\
\hline & Residual variation & Variance & SD & & & \\
\hline & Orchard & 0.07 & 0.27 & & & \\
\hline \multirow[t]{4}{*}{ Bees captured in bee bowls } & Main effect & $\chi^{2}$ & $\mathrm{df}$ & $P$ & $R_{\mathrm{m}}^{2}$ & $R^{2} \mathrm{c}$ \\
\hline & Taxon & 26.4 & 2 & $<0.001$ & 0.951 & 0.992 \\
\hline & Residual variation & Variance & SD & & & \\
\hline & Orchard & 5.08 & 2.25 & & & \\
\hline
\end{tabular}


(a)

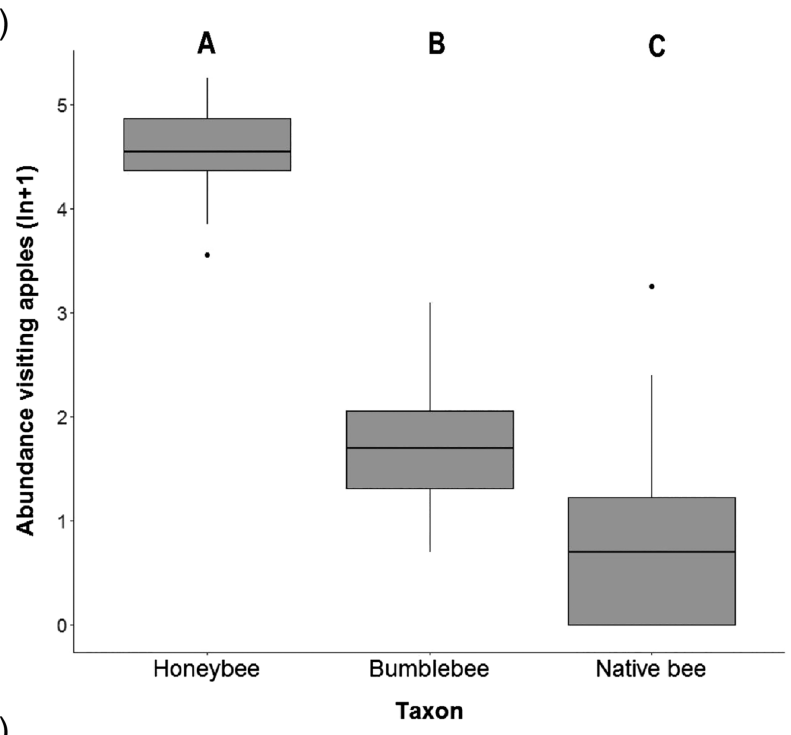

(b)

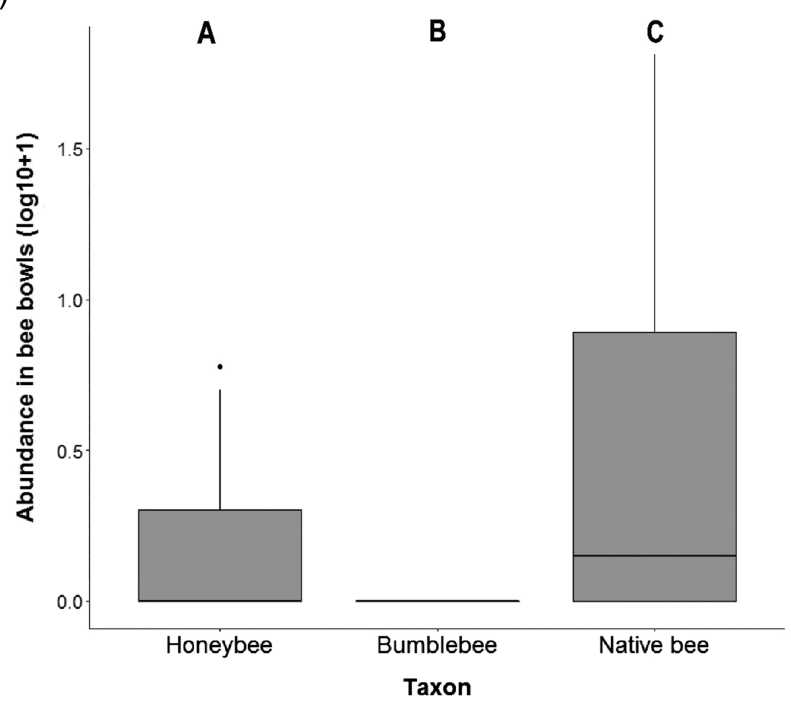

Fig. 1. Relative abundance of the European honey bee, introduced bumblebee (Bombus terrestris) and native bees on (a) apple blossoms and (b) captured in bee bowls. $N=12$. The box plots display the median (horizontal line), 25 th and 75 th percentiles (upper and lower hinges of the box), with the whiskers extending $1.5 \times$ the interquartile range (range between the upper and lower hinges). Circles represent outliers.

apple blossoms however did not differ (abundance: $P=0.571$; species richness: $P=0.206$ ) (Table 3). More species were collected from surrounding flowers than bee bowls $(P=0.001)$, whereas differences in abundance of native bees collected on surrounding flowers vs. bee bowls did not differ statistically $(P=0.117)$ (Table 3$)$.

There was no relationship between native bees recorded on surrounding flowers with native bees recorded foraging on apple blossoms for both abundance $\left(\chi^{2}=0.062, P=0.803\right.$, estimate $=-0.008, \mathrm{SE}=0.03$ and $\left.R_{\mathrm{m}}^{2}=0.001\right)$ and species richness $\left(\chi^{2}=0.004, P=0.951\right.$, estimate $=-0.02, \mathrm{SE}=0.33$ and $\left.R_{\mathrm{m}}^{2}<0.001\right)$.

\section{Relationship between introduced bees and native bees}

Neither abundance nor species richness of native bees was significantly associated with abundance of introduced bees (both
$P>0.05)$. This lack of an association was consistent for native bees collected in bee bowls, on apple blossoms and on surrounding flowers (all $P>0.05$ ) (Table 4).

\section{Weather conditions}

Abundance of both introduced bee taxa exhibited non-significant relationships with temperature $(P>0.05$; Table 5$)$. In contrast, native bee abundance and species richness was positively related to temperature (abundance: $P=0.034$; species richness: $P=0.017$; Table 5). Native bees were not observed foraging when conditions were cloudy or raining, whereas although introduced bees did not exhibit a relationship with temperature, they appeared to be more tolerant of such weather conditions. In particular, bumble bees still foraged during periods when it was overcast or there was light drizzle. 

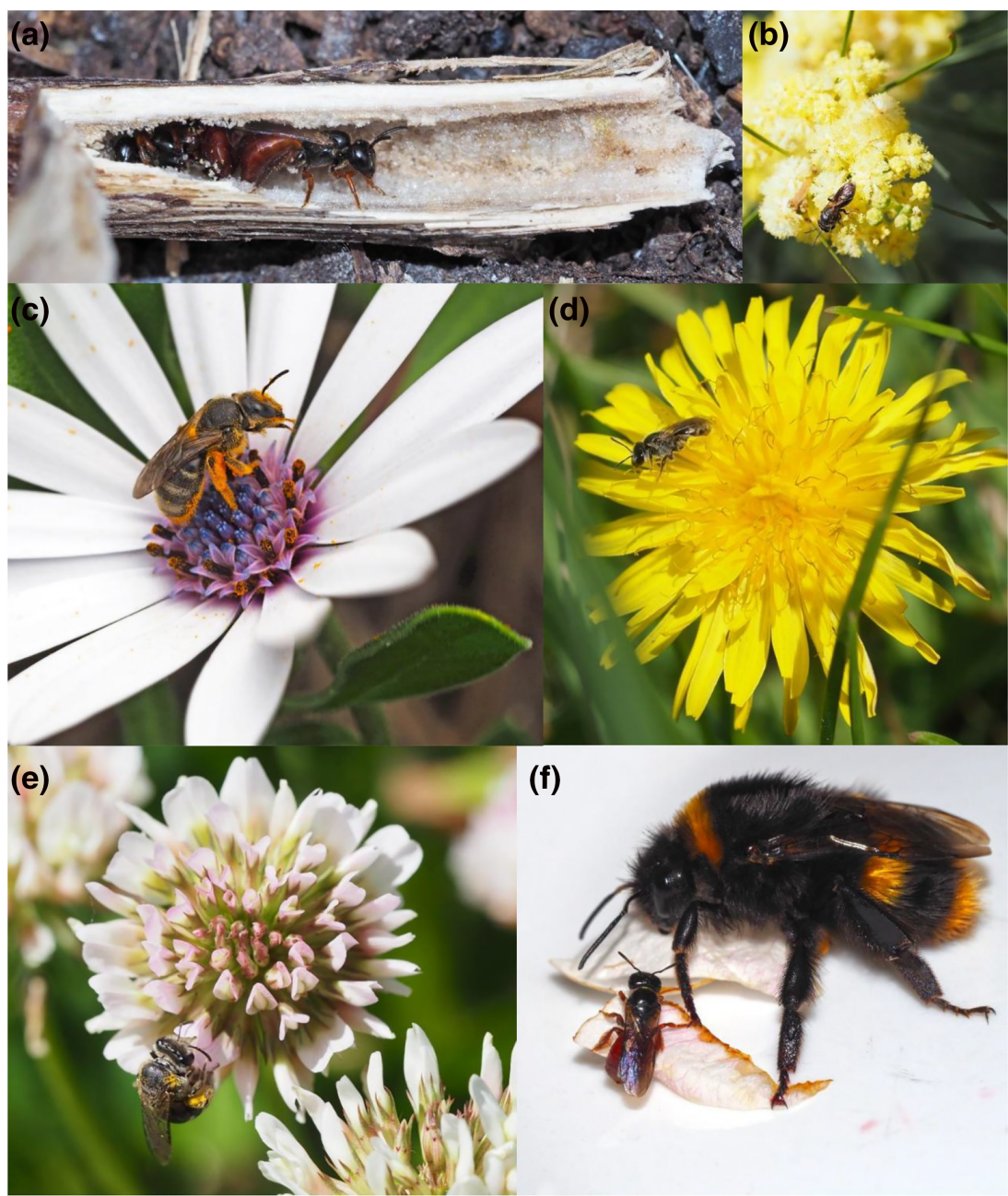

Fig. 2. Examples of native bees collected: (a) Exoneura (Exoneura) tasmanica nesting in an exotic blackberry stem; (b) Euhesma (Euhesma) fasciatella on native Acacia; (c) Lasioglossum (Chilalictus) sp. on the exotic ornamental Dimorphotheca ecklonis; (d) small halictid on the weed Taraxicum officinale; (e) Lasioglossum (Chilalictus) sp. on the exotic Trifolium repens (considered a 'weed' in apple orchards); and (f) Exoneura (Exoneura) tasmanica with an introduced queen Bombus terrestris. Images by Kit Prendergast.

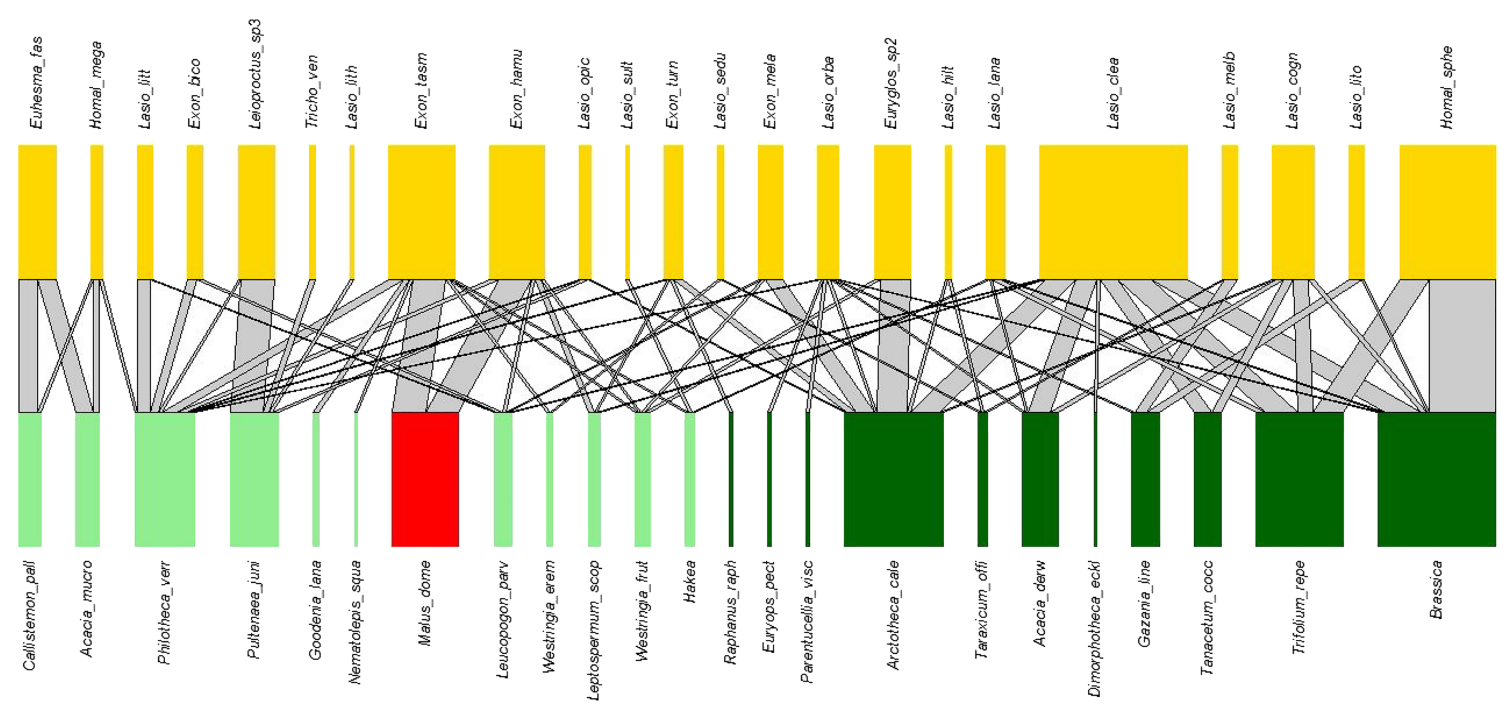

Fig. 3. Bipartite plant-bee network showing floral associations of all native bees collected across four Tasmanian apple orchards. Native bee species are on the top, and plants are on the bottom. Apple blossoms are in red, exotic plants in dark green and Australian native plants in light green. Thickness of the grey bars represents the number of bees collected on the plant. 
(a)

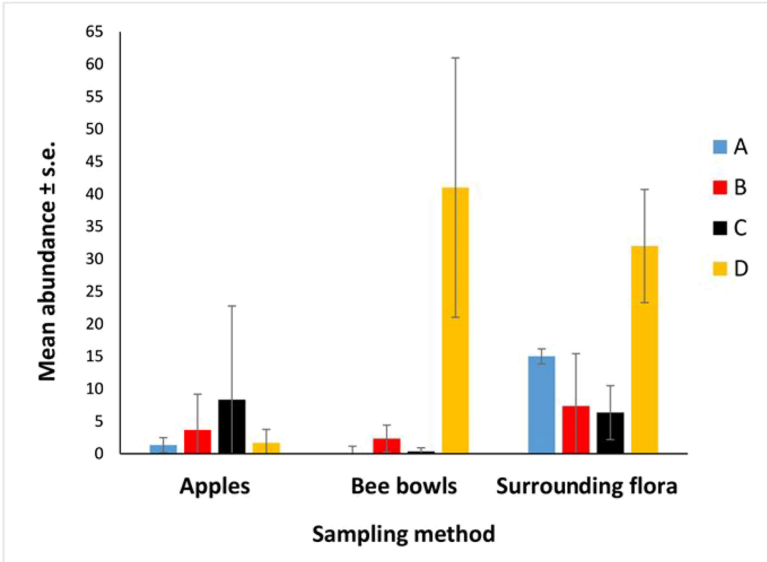

(b)

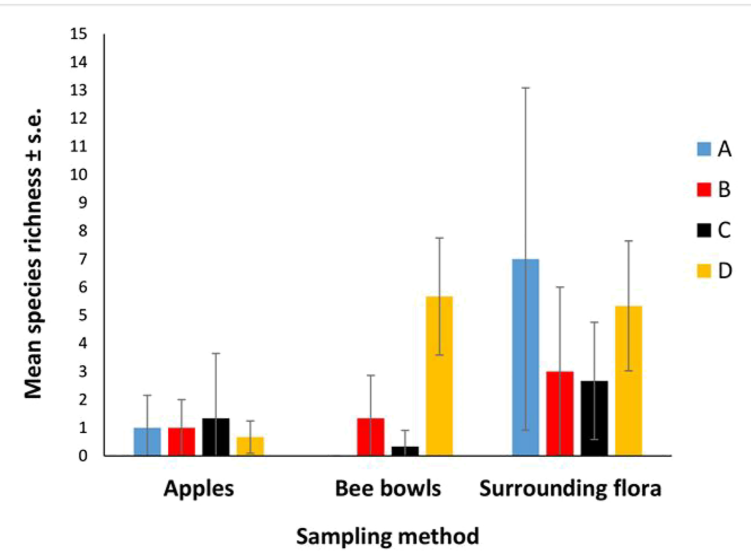

Fig. 4. Mean abundance and species richness ( $\pm \mathrm{SE}$ ) of native bees collected on apple blossoms, in bee bowls and on the surrounding flora across four apple orchards in the Huon Valley region of Tasmania. Each orchard was surveyed three times in October. Orchards A-C were Certified Organic, and Orchard D was managed under Integrated Pest Management.

\section{Variation among sites}

Although honey bees dominated assemblages across all four sites, the native bee fauna and their representation on apples, on surrounding vegetation and caught in bee bowls varied (Fig. 4), with bee bowls being relatively ineffective in the organic orchards with larger amounts of native vegetation but
Table 4 Relationship between abundance of introduced bees (Apis mellifera and Bombus terrestris) and native bee abundance and species richness $(N=12)$

\begin{tabular}{lccccc}
\hline \multicolumn{1}{c}{ Native bee abundance } & $\chi^{2}$ & $P$ & Estimate & SE & $R_{\mathrm{m}}^{2}$ \\
\hline Total & 0.49 & 0.485 & 0.005 & 0.007 & 0.042 \\
Apples & 0.17 & 0.680 & -0.004 & 0.009 & 0.016 \\
Bee bowls & 0.02 & 0.807 & -0.002 & 0.012 & 0.001 \\
Surrounding flowers & 1.28 & 0.259 & 0.008 & 0.007 & 0.132 \\
\hline Native bee species richness & $\chi^{2}$ & $P$ & Estimate & SE & $R_{\mathrm{m}}^{2}$ \\
\hline Total & 0.06 & 0.809 & -0.0007 & 0.003 & 0.006 \\
Apples & 0.25 & 0.621 & 0.003 & 0.007 & 0.021 \\
Bee bowls & 2.97 & 0.085 & 0.019 & 0.012 & 0.176 \\
Surrounding flowers & 0.112 & 0.738 & 0.003 & 0.009 & 0.042
\end{tabular}

$\chi^{2}$ and $P$ values are based on ANOVAs between a model with and without introduced bee abundance as the explanatory variables. Orchard was included as a random effect in all models. Native bee abundance was modelled with negative binomial models, whereas species richness was modelled with generalised linear mixed-effect models with a Poisson distribution. The estimate and associated standard error (SE) were produced from a summary of the model containing introduced bee abundance as a main effect. $R_{\mathrm{m}}^{2}$ (marginal $R^{2}$ ) provides the variance explained by introduced bee abundance.

were effective in the IPM orchard D, which lacked native flora in or around the orchard.

Each orchard had at least one species found exclusively at that site (Fig. 5). The greatest number of bees exclusive to a site (eight species) was recorded at orchard A, including genera not recorded elsewhere (Euhesma and Trichocolletes). In addition to the introduced honey bees and bumble bees, two native species - Lasioglossum (Chilalictus) orbatum and Lasioglossum (Chilalictus) clelandi - were shared between all sites, both of which are medium-sized, generalised, ground-nesting halictids (Prendergast 2020b). [Correction added on 11 February 2021, after first online publication: 'cleandi' has been corrected].

Beta diversity was fairly low, with only moderate differentiation among orchard in their bee assemblage, with almost an equal contribution of turnover and nestedness (i.e. replacement and richness beta-diversity components) to the overall differentiation among sites (Table 6).

\section{DISCUSSION}

In some landscapes and for some crops, honey bees contribute only a fraction of pollination services (Garibaldi et al. 2013; Garratt et al. 2016). Yet our results found honey bees to be the

Table 3 Differences between sampling location (apple blossoms, surrounding flowers and bee bowls) in abundance and species richness of native bees

\begin{tabular}{|c|c|c|c|c|c|c|}
\hline Native bee abundance & Main effect & $\chi^{2}$ & $\mathrm{df}$ & $P$ & $R_{\mathrm{m}}^{2}$ & $R^{2} \mathrm{c}$ \\
\hline & Sampling location & 11.7 & 2 & 0.003 & 0.239 & 0.431 \\
\hline & Residual variation & Variance & SD & & & \\
\hline & Orchard & 0.33 & 0.58 & & & \\
\hline \multirow[t]{4}{*}{ Native bee species richness } & Main effect & $\chi^{2}$ & df & $P$ & $R_{\mathrm{m}}^{2}$ & $R^{2} \mathrm{c}$ \\
\hline & Sampling location & 31.8 & 2 & $<0.001$ & 0.435 & 0.547 \\
\hline & Residual variation & Variance & SD & & & \\
\hline & Orchard & 0.10 & 0.32 & & & \\
\hline
\end{tabular}


Table 5 Relationship between bees and daily maximum temperature

\begin{tabular}{lcccccc}
\hline Taxon & $\chi^{2}$ & $\mathrm{df}$ & $P$ & Estimate & SE & $R_{\mathrm{m}}^{2}$ \\
\hline A. mellifera & 0.21 & 1 & 0.648 & -0.01 & 0.03 & 0.014 \\
B. terrestris & 0.12 & 1 & 0.726 & -0.01 & 0.04 & 0.006 \\
Native bee abundance & 4.59 & 1 & 0.032 & 0.12 & 0.05 & 0.277 \\
Native bee species richness & 5.67 & 1 & 0.017 & 0.07 & 0.03 & 0.334 \\
\hline
\end{tabular}

For Bombus terrestris and native bee species richness, generalised linear mixed-effect models were used, whereas negative binomial glmers were used for Apis mellifera and native bee abundance.

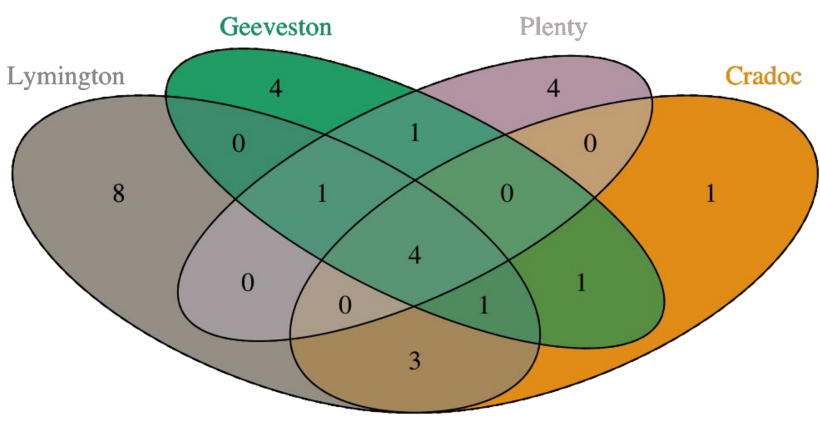

Fig. 5. Venn diagram showing shared and unique bee species between the four Tasmanian apple orchards.

Table 6 Beta diversity among the four Tasmanian apple orchards

\begin{tabular}{lcc}
\hline Beta-diversity component & Average & Variance \\
\hline Btotal & 0.419 & 0.003 \\
Brepl & 0.192 & 0.002 \\
Brich & 0.227 & 0.002 \\
\hline
\end{tabular}

Calculated beta diversity of the four sites simultaneously, with average and variance among all pairwise comparisons (Legendre 2014).

Brepl, beta diversity explained by replacement of species alone; Brich, beta diversity explained by species loss/gain (i.e. richness differences) alone; Btotal, total beta diversity, which reflects both species replacement and loss/ gain.

main visitors to Tasmanian apple flowers and therefore suggest that honey bees are likely to be the main pollinators. This result is consistent with other research where honey bees have been found to be the primary pollinators of apple (Free 1993; Ramírez \& Davenport 2013; Pardo \& Borges 2020), or even their sole visitors (Geslin et al. 2017).

There has been little published research on apple flower visitors in Australia; however, research to date in other states of Australia has found that honey bees are also the main visitors to apple blossoms (Somerville 1999; Keogh et al. 2010b). Research conducted in New South Wales revealed that honey bees comprise $97 \%$ of insect visitors to apple blossoms (Somerville 1999). Furthermore, honey bee exclusion from apple trees causes significant reductions in fruit set and yield per tree (Langridge \& Jenkins 1970). In New Zealand, the only pollinating insects across seven apple varieties were honey bees, and to a lesser extent Bombus terrestris, with bee exclusion likewise resulting in only trace fruit set (Palmer-Jones \& Clinch 1966, 1967, 1968). It therefore appears that in Australia, and particularly in Tasmania as our results seem to suggest, pollinators other than Apis mellifera are unlikely to satisfy the pollination requirements of commercial apple orchards.

The discrepancy between studies documenting a rich native bee pollinator assemblage visiting apple orchards (e.g. Földesi et al. 2016: Szabolcs-Szatmár-Bereg, Hungary; Russo et al. 2015: New York, USA) and the present study where native bees were scarce is likely to stem from the biogeography of the Australian continent, which has experienced long periods of evolution in isolation from other flora and fauna (Michener 1979; Hopper 2009; Brown \& Cunningham 2019). The plant family Rosaceae is only a minor component of the Australian flora, with only 26 native species out of an estimated 21000 species of native flora (Australian National Botanic Gardens and Centre for Australian National Biodiversity Research (ANBGCANBR) 2015; Messina 2020), and thus not a major component in the evolutionary history of Australian native bees. Many native bees instead are specialists on native flora, many of which are endemic (Houston 2018). Furthermore, bees often prefer native flora over exotic flora (Williams et al. 2011; Morandin \& Kremen 2013). Our results suggest that honey bees may be required to fulfil the pollination needs of apple in geographical regions where this crop is an introduced species and where the native bee communities are infrequent visitors; however, whether this applies to other regions of the world still needs to be investigated.

Honey bees comprised the vast majority of visits to apples, yet managed honey bee colonies were kept on the premises only in orchard D. As surrounding properties were not known to host managed honey bee colonies in the organic orchards (orchards A-C) (based on discussion with the orchard owners), it appears that a substantial proportion of the honey bee visitors were likely to be feral honey bees. This situation does not appear to be unusual: many apple growers achieve adequate pollination by relying on feral bees or honey bees from colonies managed for honey production in the landscape (Somerville 1999). However, feral honey bees can be detrimental to wildlife by usurping nesting hollows of hollow-nesting birds and mammals (New 2005; Berris \& Barth 2020) and can pose a risk to managed bees through competition for food resources and disease transmission (Pirk et al. 2017). More intensive surveys into the reliance of apple production on feral honey bee colonies are required, and an investigation into the economics of removal of feral colonies and partnerships between growers and apiarists in having managed hives on site to achieve optimal yield and/or quality. Partnerships between apiarists and apple growers may be fruitful in this respect (Keogh et al. 2010a), whilst ensuring that temporary honey bee hives are not at levels that can cause competitive impacts on resident native bees or spread diseases.

Previous studies on the relative pollination efficiency of different bee taxa have often found that even when honey bees are as efficient, or less efficient, than native bees, their overall pollination services are superior by virtue of their greater abundances (Park et al. 2016). Indeed, honey bees far outnumbered 
native bees on the apple orchards, emphasising the need for ongoing research in Australia into bee biosecurity against introduced parasites and diseases (e.g. Varroa mite) (Iwasaki et al. 2015) and improving honey bee management for apple pollination services (Stern et al. 2001).

Bombus terrestris were common visitors to apple blossoms, including under weather conditions that were suboptimal foraging conditions for most other bees (Linsley 1978; Riessberger \& Crailsheim 1997; Goulson 2003; Joshi \& Joshi 2010; Tuell \& Isaacs 2010; Brittain et al. 2013; Güler \& Dikmen 2013). Periods of inclement weather are common in Tasmania during the period of apple bloom; hence, this introduced species may be providing consistent pollination services. This must be weighed up against the potential negative environmental impacts of bumble bees (Stout \& Goulson 2000).

With the majority of bumble bees collected being queens, this suggests sampling coincided with the period in which queens had recently emerged from winter hibernation and were in early establishment of colonies (Goulson 2003). This points to a potential control strategy, whereby queens can be targeted and eliminated to reduce propagation of new colonies. Blue vane traps have been demonstrated to be particularly attractive to Bombus (Stephen \& Rao 2005; Prendergast et al. 2020); however, by-catch of non-target bees in Tasmania needs to be established.

The differential activity of bee taxa in relation to temperature is in line with differential sensitivity based on origin and body size, with the activity of the larger, hairy, temperate-origin introduced bees being unaffected by temperature, whereas the activity of smaller-sized native bees, better adapted to the warmer climate of Australia, was positively related (Fig. 3f). The increased activity of native bees has implications for climate change, where it may be that native bees play an increasingly important role under predicted higher temperatures (Antarctic Climate and Ecosystems Cooperative Research Centre (ACE CRC) 2010). There was considerable variation between orchards in wild bee abundance and diversity (Fig. 4), and although temperature did not consistently co-vary with orchard surveyed (Fig. S1), this may explain some of the variation between sites.

Wild bees often augment pollination services (Viana et al. 2014; Blitzer et al. 2016; Park et al. 2016; Miñarro \& García 2018) and may enhance honey bee pollination services by altering their foraging behaviour (Greenleaf \& Kremen 2006). Planting alternative foraging plants in and among the apple trees and ensuring there are adequate nesting resources in the orchards may enhance native bee populations and encourage native bee visitation (Campbell et al. 2017). For example, Exoneura were observed visiting apple flowers, and their populations can be enhanced by providing bundles of reeds and pithy stems, whereas for Lasioglossum, they require patches of bare soil for nesting (Houston 2018). That Exoneura and Lasioglossum were the main native bee visitors to apples, with other taxa such as Homalictus being present but foraging only on weedy understorey flora are consistent with Brown et al. (2020). This suggests that Exoneura and Lasioglossum are the best candidates in Australia to focus on for wild bee pollination services to apple. The main native bee visitors, Exoneura, were most abundant at the orchard, which had lots of blackberry, with the Exoneura using the old pithy stems for nesting (Fig. 3a). This suggests that provision of nesting resources is important for encouraging these native apple visitors (Lye et al. 2009; Roulston \& Goodell 2011). Blackberry, however, is a highly invasive species in Tasmania (Department of Primary Industries, Parks, Water and Environment (DPIPWE) (Tasmania) 2019). Recommendations from this research would be to (i) ensure bees are not nesting in blackberry stems before removing it and (ii) provide alternative native substrates for these native bees to use if blackberry removal is to take place, e.g. pithy centres of dead stems, reeds and/or twigs of native plants, e.g. Xanthorrhoea (Schwarz \& Blows 1991; Sugden \& Pyke 1991; Silberbauer 1992).

For sustainable apple production in Tasmania, and indeed abroad, beekeeping practices need to be integrated with promoting the biodiversity of native bees in farm systems to include non-crop species (Kleijn et al. 2015; Senapathi et al. 2015; Prendergast 2020a). Although we did not find negative associations between introduced bees and native bees, honey bees always dominated the assemblages and there was little variation in the relative proportions of honey bees and native bees, making determining potential competitive impacts difficult in this study.

Although native bees were only minor components during most surveys of the apple orchards, a relatively high diversity and abundance of native bees was collected on native flowers surrounding the apple orchards. This reveals that in this region, provided native vegetation is retained, native bees can still persist. If native flora are planted interspersed among the apple trees, this may encourage native bees to move into the orchards and also forage on the apple flowers (Campbell et al. 2017; Wu et al. 2019). Even if this does not result in spillover into apples (Nicholson et al. 2020), supporting bee biodiversity is important for wildflowers in native ecosystems and the ecosystem services these habitats provide (Kremen et al. 2007) and also has high intrinsic value (Kleijn et al. 2015; Prendergast 2020a). The floral associations of native bees observed in the present study are similar to those by Hingston (1999), who found that Halictidae visited a taxonomically diverse range of flowers, and native Fabaceae and Ericaceae were important floral resources for a range of native bee species in Tasmania. Future studies are required to perform floristic surveys concurrently with bee surveys to evaluate how the floristic community (abundance, species richness and composition) influence native bee communities in and around apple orchards. Bees in the family Megachilidae are known to be effective apple pollinators (Vicens $\&$ Bosch 2000; Wei et al. 2002) and frequent visitors to apple orchards (Sheffield et al. 2008). Yet no megachilids were observed. This is likely due to (i) megachilids not being active at this time of year (based on surveys conducted in Western Australia; Prendergast 2020d); (ii) the fact that alternative foraging resources, or nesting resources, were not present in the vicinity; and (iii) the fact that megachilids are rare, being only a minor component of the Tasmanian bee fauna (Hingston 1999; PaDIL 2020). Installing trap nests (bee hotels) (Sheffield et al. 2008; Prendergast 2018; Prendergast et al. 2020) and more regular field surveys in the region could establish the cause of their absence during this survey. 
Numerous other studies have revealed the importance of wildflower plantings and native vegetation in supporting diverse wild bees, and even honey bees, around apple orchards (Sheffield et al. 2013; Földesi et al. 2016; Joshi et al. 2016; Campbell et al. 2017; Wu et al. 2019). Diversification of non-crop resources should support a greater diversity and abundance of native bees, both those that visit the apple crop and those that contribute to the biodiversity of native bees in the region (Guzman et al. 2019).

In orchard $\mathrm{D}$, there was virtually no native vegetation in the immediate vicinity; however, a very high abundance of halictids were collected in the bee bowls and, in particular, foraging on the weeds in and around the apple orchard. This may represent a concentrating effect, whereby with less native vegetation, the bees were concentrated on the prolific weeds. There is also evidence to suggest that conversion of forest to open agricultural habitats can favour halictids - ground-nesting generalist bees by enhancing nesting substrates (open ground) and floral resources (Lentini et al. 2012; Harrison et al. 2018; Hall et al. 2019; Brown et al. 2020). The high abundance of native bees on 'weeds' (Fig. 2c-e) emphasises the value of 'weedy' species in agricultural settings and argues against eliminating these species (Marshall et al. 2003; Frankie et al. 2013; Bretagnolle \& Gaba 2015; Requier et al. 2015; Lowenstein et al. 2019; Brown et al. 2020).

Although low sample size limits the confidence in conclusions, a number of points can be made comparing the turnover among sites that warrant further investigation. Firstly, it appears that bee bowls appear most effective in relatively 'poor' habitat from the point of view for supporting a more diversified and specialised bee assemblage. This has implications when exclusively using bee bowls to gauge the relative value of habitats, and indeed, previous studies have suggested that bee bowls are more effective in resource-poor habitats (Mayer 2005; Roulston et al. 2007; Baum \& Wallen 2011; Prendergast et al. 2020), and are biased towards sampling halictids in habitats where there are few alternative flowering resources (e.g. crop fields), but perform poorly at sampling species-rich native bee assemblages in floristically rich habitats (Prendergast et al. 2020). Bee bowls were moreover ineffective at collecting the dominant apple flower visitors, consistent with other studies that have found that bee bowls are ineffective at accurately sampling honey bees and bumble bees (Wagner et al. 2014; Buchanan et al. 2017; Prendergast et al. 2020). It is evident that if bee bowls had been deployed only, this would have completely mischaracterised that bee assemblage visiting the apple orchards.

Secondly, contrasting with species-area relationships (Taki et al. 2018), the smallest orchard had the greatest number of species unique to that habitat. This may be attributed to the high amounts of native flora in the surroundings. Indeed, the two genera exclusively found in this orchard (Euhesma, represented by Euhesma fasciatella, and Trichocolletes, represented by Trichocolletes venustus) both were collected exclusively on native pea plants (Fabaceae).

Amazingly, each site, despite being in the same geographical region and representing same dominant habitat type (apple orchard), had at least one species unique to that site. Although greater sampling effort may have uncovered a greater similarity among sites, this nevertheless high turnover indicated that each orchard had its own unique contribution to the regional diversity in this habitat type. As expected, honey bees occurred across all sites, as well as two generalist halictids and bumble bees. This latter finding underscores the establishment of this introduced species across Tasmania.

The results presented here also are important in contributing to the documenting of Australia's native bee diversity (Batley $\&$ Hogendoorn 2009). Indeed, there have been very few surveys of native bees in Tasmania, and these have largely been conducted in solely natural habitats (McQuillan \& Hingston 1999; Hingston 2002). Moreover, results here also provide information on what native flora the bees around orchards forage on, and by documenting which bees occur, their specific requirements, including not just food resources but also nesting habitats, can be catered for. This will go towards creating orchards that support native bee biodiversity. Such advice to growers is severely lacking in Tasmania, and Australia in general, which contrasts with the wealth of information about supporting wild native bee taxa around apple orchards overseas (e.g. Park 2012; Földesi et al. 2016; Sheffield et al. 2016).

\section{ACKNOWLEDGEMENTS}

K. S. P. would like to firstly thank the orchard owners who kindly permitted her to survey their orchards: Roslyn and Anthony Mangold of Old Post Office Farm; Matthew and Coreen Tack of Our Mate's Farm; Christine and Mark Duggan of Duggan's Apples; and Andrew Hall of Reid's Fruit. K. S. P. would also like to thank Geoff Allen of University of Tasmania for kindly loaning her field equipment, Andrew Smith of Willie Smith's Apples for providing her information about the Tasmanian apple industry, her family in Tasmania for providing such a warm welcome, her hosts for being so accommodating and letting her babysit joeys, and Rob Manning and Liz Barbour for feedback on a draft of the manuscript. K. S. P. would like to thank Freda and John Hamblin for their financial contribution to funding this project. We received financial support from the FNRS/FWO joint programme 'EOS - Excellence of Science' for the project 'CliPS: Climate change and its impact on Pollination Services' (project 30947854), which made the apple surveys in Tasmania possible. We would also like to thank the three reviewers for their constructive feedback for improving the manuscript.

\section{REFERENCES}

Antarctic Climate and Ecosystems Cooperative Research Centre (ACE CRC). 2010. Climate Futures for Tasmania General Climate Impacts: The Summary. Antarctic Climate and Ecosystems Cooperative Research Centre, Hobart, Tasmania.

Australian National Botanic Gardens and Centre for Australian National Biodiversity Research (ANBGCANBR). 2015. Australian flora statistics, in Australian National Botanic Gardens and Centre for Australian 
National Biodiversity Research. Available from: https://www.anbg.gov. au/aust-veg/australian-flora-statistics.html [Accessed 18 Nov 2020]

Australian Organic Ltd (2019). Australian Certified Organic Standard: the requirements for organic certification 2019 - version 1. Australian Organic Ltd. Nundah, QLD. Available from: https://aco.net.au/Downloads/ACOS_2017_V1.pdf [Accessed 18 Feb 2020]

Barton K. 2019. MuMIn: multi-model inference. R package version 1.43.15. Available from: https://CRAN.R-project.org/package=MuMIn [Accessed 2 May 2020]

Bates D, Maechler M, Bolker BM \& Walker S. 2015. Fitting linear mixed-effects models using lme4. Journal of Statistical Software 67, $1-48$.

Batley M \& Hogendoorn K. 2009. Diversity and conservation status of native Australian bees. Apidologie 40, 347-354.

Batley M \& Houston TF. 2012. Revision of the Australian bee genus Trichocolletes Cockerell (Hymenoptera: Colletidae: Paracolletini). Records of the Australian Museum 64, 1-50.

Baum KA \& Wallen KE. 2011. Potential bias in pan trapping as a function of floral abundance. Journal of the Kansas Entomological Society 84, $155-115$.

Berris KK \& Barth M. 2020. PVC nest boxes are less at risk of occupancy by feral honey bees than timber nest boxes and natural hollows. Ecological Management and Restoration 21, 155-157.

Blitzer EJ, Gibbs J, Park MG \& Danforth BN. 2016. Pollination services for apple are dependent on diverse wild bee communities. Agriculture, Ecosystems \& Environment 221, 1-7.

Bosch J \& Kemp WP. 2002. Developing and establishing bee species as crop pollinators: the example of Osmia spp.(Hymenoptera: Megachilidae) and fruit trees. Bulletin of Entomological Research 92, 3-16.

Bretagnolle V \& Gaba S. 2015. Weeds for bees? A review. Agronomy for Sustainable Development 35, 891-909.

Brittain C, Kremen C \& Klein A-M. 2013. Biodiversity buffers pollination from changes in environmental conditions. Global Change Biology 19, $540-547$.

Brooks ME, Kristensen K, van Benthem KJ et al. 2017. glmmTMB balances speed and flexibility among packages for zero-inflated generalized linear mixed modeling. The R Journal 9, 378-400.

Brown J, Barton PS \& Cunningham SA. 2020. Flower visitation and land cover associations of above ground- and below ground-nesting native bees in an agricultural region of south-east Australia Agriculture. Ecosystems \& Environment 295, 106895.

Brown J \& Cunningham SA. 2019. Global-scale drivers of crop visitor diversity and the historical development of agriculture. Proceedings of the Royal Society B: Biological Sciences 286, 20192096. https:/doi.org/ 10.1098/rspb.2019.2096.

Buchanan A, Gibbs J, Komondy L \& Szendrei Z. 2017. Bee community of commercial potato fields in Michigan and Bombus impatiens visitation to neonicotinoid-treated potato plants. Insects $\mathbf{8}, 30$.

Buckley LB \& Kingsolver JG. 2012. Functional and phylogenetic approaches to forecasting species' responses to climate change. Annual Review of Ecology, Evolution, and Systematics 43, 205-226.

Campbell AJ, Wilby A, Sutton P \& Wäckers FL. 2017. Do sown flower strips boost wild pollinator abundance and pollination services in a spring-flowering crop? A case study from UK cider apple orchards. Agriculture, Ecosystems \& Environment 239, 20-29.

Cardoso P, Rigal F \& Carvalho JC. 2015. BAT - Biodiversity Assessment Tools, an R package for the measurement and estimation of alpha and beta taxon, phylogenetic and functional diversity. Methods in Ecology and Evolution 6, 232-236.

Carvalho JC, Cardoso P \& Gomes P. 2012. Determining the relative roles of species replacement and species richness differences in generating beta-diversity patterns. Global Ecology and Biogeography 21, 760-771.

Christmann S \& Aw-Hassan AA. 2012. Farming with alternative pollinators (FAP) - an overlooked win-win-strategy for climate change adaptation. Agriculture, Ecosystems \& Environment 161, 161-164.

Cockerell TDA. 1905. Descriptions and records of bees. V. Annals and Magazine of Natural History 7 (16), 465-477.

Cockerell TDA. 1914. New Australian bees. Entomologiste 47, 197-201.

Cockerell TDA. 1918. Some bees collected in Queensland. Memoirs of the Queensland Museum 6, 112-120.

Cockerell TDA. 1930. New Australian bees. Memoirs of the Queensland Museum 10, 37-50.
Department of Primary Industries and Regional Development. 2017. Recommendations for successful apple pollination. In Agriculture and FoodPome fruit. Government of Western Australia, Western Australia.

Department of Primary Industries, Parks, Water and Environment (DPIPWE) (Tasmania). 2019. Blackberry. In Invasive Species. Department of Primary Industries, Parks, Water and Environment (Tasmania), Tasmania.

Dulta P \& Verma L. 1987. Role of insect pollinators on yield and quality of apple fruit. Indian Journal of Horticulture 44, 274-279.

Exley EM. 1976. Revision of the subgenus Euryglossa Smith (Apoidea: Colletidae: Euryglossinae). Australian Journal of Zoology Supplementary Series 24 (41), 1-72.

Földesi R, Kovács-Hostyánszki A, Körösi Á et al. 2016. Relationships between wild bees, hoverflies and pollination success in apple orchards with different landscape contexts. Agricultural and Forest Entomology 18 (1), 68-75. https://doi.org/10.1111/afe.12135

Fox J. 2015. Applied Regression Analysis and Generalized Linear Models. Sage Publications, Thousand Oaks, California.

Frankie GW, Vinson SB, Rizzardi MA et al. 2013. Relationships of bees to host ornamental and weedy flowers in urban Northwest Guanacaste Province, Costa Rica. Journal of the Kansas Entomological Society 86, 325-351.

Free JB. 1966. The pollinating efficiency of honey-bee visits to apple flowers. Journal of Horticultural Science 41 (1), 91-94.

Free JB. 1993. Insect Pollination of Crops. Academic Press, London, UK.

Fruit Growers Tasmania. 2019. Fruit Growers Tasmania: about Tasmania. Fruit Growers Tasmania, Tasmania.

Garibaldi LA, Steffan-Dewenter I, Kremen C et al. 2011. Stability of pollination services decreases with isolation from natural areas despite honey bee visits. Ecology Letters 14 (10), 1062-1072.

Garibaldi LA, Steffan-Dewenter I, Winfree R et al. 2013. Wild pollinators enhance fruit set of crops regardless of honey bee abundance. Science 339 (6127), 1608-1611.

Garratt MP, Breeze T, Boreux V et al. 2016. Apple pollination: demand depends on variety and supply depends on pollinator identity. PLOS ONE 11, e 0153889 .

Garratt MP, Breeze TD, Jenner N, Polce C, Biesmeijer JC \& Potts SG. 2014. Avoiding a bad apple: insect pollination enhances fruit quality and economic value. Agriculture, Ecosystems \& Environment 184, 34-40.

Geslin B, Aizen MA, Garcia N, Pereira A-J, Vaissière BE \& Garibaldi LA. 2017. The impact of honey bee colony quality on crop yield and farmers' profit in apples and pears. Agriculture, Ecosystems \& Environment 248, $153-161$.

Gibbs DM \& Muirhead IF. 1998. The economic value and environmental impact of the Australian beekeeping industry.

Goodell K \& Thomson JD. 1997. Comparisons of pollen removal and deposition by honey bees and bumble bees visiting apple, pp. 103-108. International Society for Horticultural Science (ISHS), Leuven, Belgium.

Goodman R. 1994. Honey bee pollination of fruit tree crops (ed. Agriculture Victoria). Victoria State Government, Victoria.

Goulson D. 2003. In: Bumblebees, Their Behaviour and Ecology, pp. 235 Oxford University Press, Oxford, UK ISBN 0-19-852607-5.

Greenleaf SS \& Kremen C. 2006. Wild bees enhance honey bees' pollination of hybrid sunflower. Proceedings of the National Academy of Sciences 103, 13890-13895.

Grose MR, Barnes-Keoghan I, Corney SP et al. 2010. Climate Futures for Tasmania: General Climate Impacts Technical Report. Antarctic Climate $\&$ Ecosystems Cooperative Research Centre, Hobart, Tasmania.

Güler Y \& Dikmen F. 2013. Potential bee pollinators of sweet cherry in inclement weather conditions. Journal of the Entomological Research Society 15, 9-19.

Guzman A, Chase M \& Kremen C. 2019. On-farm diversification in an agriculturally-dominated landscape positively influences specialist pollinators. Frontiers in Sustainable Food Systems 3, 87.

Hall B. 2014. Apple of the Huon. In Tasmanian Geographic. Tasmanian Geographic

Hall MA, Nimmo DG, Cunningham SA, Walker K \& Bennett AF. 2019. The response of wild bees to tree cover and rural land use is mediated by species' traits. Biological Conservation 231, 1-12.

Harrison T, Gibbs J \& Winfree R. 2018. Forest bees are replaced in agricultural and urban landscapes by native species with different phenologies and life-history traits. Global Change Biology 24 (1), 287-296. 
Hartig F. 2020. DHARMa: residual diagnostics for hierarchical (multi-level/ mixed) regression models. The Comprehensive R Archive Network (CRAN), R package version 0.3. 2.0.

Hingston AB. 1999. Affinities between southern Tasmanian plants in native bee visitor profiles. Australian Journal of Zoology 47, 361-384.

Hingston AB. 2002. Pollination ecology of Eucalyptus globulus subsp. globulus and Eucalyptus nitens (Myrtaceae). In School of Geography and Environmental Studies vol. Doctor of Philosophy. University of Tasmania, Tasmania.

Hingston AB. 2006. Is the exotic bumble bee Bombus terrestris really invading Tasmanian native vegetation? Journal of Insect Conservation 10, 289-293.

Hogendoorn K, Gross CL, Sedgley M \& Keller MA. 2006. Increased tomato yield through pollination by native Australian Amegilla chlorocyanea (Hymenoptera: Anthophoridae). Journal of Economic Entomology 99, $828-833$.

Hopper SD. 2009. OCBIL theory: towards an integrated understanding of the evolution, ecology and conservation of biodiversity on old, climatically buffered, infertile landscapes. Plant and Soil 322, 49-86.

Houston TF. 2018. A Guide to the Native Bees of Australia. CSIRO Publishing, Clayton South, Victoria.

Iwasaki JM, Barratt BI, Lord JM, Mercer AR \& Dickinson KJ. 2015. The New Zealand experience of varroa invasion highlights research opportunities for Australia. Ambio 44, 694-704.

Joshi NC \& Joshi P. 2010. Foraging behaviour of Apis spp. on apple flowers in a subtropical environment. New York Science Journal 3, 71-76.

Joshi NK, Otieno M, Rajotte EG, Fleischer SJ \& Biddinger DJ. 2016. Proximity to woodland and landscape structure drives pollinator visitation in apple orchard ecosystem. Frontiers in Ecology and Evolution 4,38

Keogh RC, Mullins IJ \& Robinson AP. 2010a. Pollination aware case study: apple. In Pollination Aware, vol. RIRDC Publication No 10/109 (ed. AgriFutures Australia). AgriFutures.

Keogh RC, Robinson AP \& Mullins IJ. 2010b. Pollination aware - the real value of pollination in Australia (ed. RIRaD Corporation). Rural Industries Research and Development Corporation.

Kingston AB \& Mcquillan PB. 1998. Does the recently introduced bumble bee Bombus terrestris (Apidae) threaten Australian ecosystems? Australian Journal of Ecology 23, 539-549.

Kleijn D, Winfree R, Bartomeus I et al. 2015. Delivery of crop pollination services is an insufficient argument for wild pollinator conservation. Nature Communications 6 (1), 1-9.

Klein A-M, Vaissiere BE, Cane JH et al. 2007. Importance of pollinators in changing landscapes for world crops. Proceedings of the Royal Society of London B: Biological Sciences 274, 303-313.

Korner-Nievergelt F, Roth T, Felten S, Guelat J, Almasi B \& KornerNievergelt P. 2015. Bayesian Data Analysis in Ecology Using Linear Models with R, BUGS and Stan. Elsevier, London, UK.

Kremen C, Williams NM, Aizen MA et al. 2007. Pollination and other ecosystem services produced by mobile organisms: a conceptual framework for the effects of land-use change. Ecology Letters 10 (4), 299-314.

Langridge D \& Jenkins P. 1970. The role of honey bees in pollination of apples. Australian Journal of Experimental Agriculture 10, 366-368.

Legendre P (2014) Interpreting the replacement and richness difference components of beta diversity. Global Ecology and Biogeography, 23 (11), 1324-1334. https://doi.org/10.1111/geb.12207

Lenth RV. 2016. Least-squares means: the R package 1smeans. Journal of Statistical Software 69, 1-33.

Lentini PE, Martin TG, Gibbons P, Fischer J \& Cunningham SA. 2012. Supporting wild pollinators in a temperate agricultural landscape: maintaining mosaics of natural features and production. Biological Conservation 149, 84-92.

Linsley EG. 1978. Temporal patterns of flower visitation by solitary bees, with particular reference to the southwestern United States. Journal of the Kansas Entomological Society 1978, 531-546.

Lowenstein DM, Matteson KC \& Minor ES. 2019. Evaluating the dependence of urban pollinators on ornamental, non-native, and 'weedy' floral resources. Urban Ecosystem 22, 293-302.
Luby J. 2003. Taxonomic classification and brief history. In: Apples - Botany, Production and Uses (eds D Ferree \& I Warrington). Cabi Publishing, Oxon.

Lüdecke D, Makowski D, Waggoner P \& Patil I. 2020. Performance: assessment of regression models performance, 2020. CRAN, R package. DOI: https://doi.org/10.5281/zenodo.3952174, R package. Available from URL: https://easystats.github.io/performance/ [Accessed 2 May 2020]

Lye G, Park K, Osborne J, Holland J \& Goulson D. 2009. Assessing the value of Rural Stewardship schemes for providing foraging resources and nesting habitat for bumble bee queens (Hymenoptera: Apidae). Biological Conservation 142, 2023-2032.

Mader E, Spivak M \& Evans E. 2010. Managing alternative pollinators: a guide for growers, beekeepers, and conservationists. Sustainable Agriculture Research and Education. Handbook 11.

Mallinger RE \& Gratton C. 2015. Species richness of wild bees, but not the use of managed honey bees, increases fruit set of a pollinator-dependent crop. Journal of Applied Ecology 52, 323-330.

Marshall E, Brown V, Boatman N, Lutman P, Squire G \& Ward L. 2003. The role of weeds in supporting biological diversity within crop fields. Weed Research 43, 77-89.

Martins KT, Gonzalez A \& Lechowicz MJ. 2015. Pollination services are mediated by bee functional diversity and landscape context. Agriculture, Ecosystems \& Environment 200, 12-20.

Mayer C. 2005. Does grazing influence bee diversity? In: African Biodiversity: Molecules, Organisms, Ecosystems (eds BA Huber, BJ Sinclair, K-H, Lampe) pp. 173-179. Springer Verlag US, Boston, MA.

McConnell A \& Servant N. 1999. The history and heritage of the Tasmanian apple industry - a profile Queen Victoria Museum and Art Gallery, Launceston.

Rader R, Reilly J, Bartomeus I \& Winfree R. 2013. Native bees buffer the negative impact of climate warming on honey bee pollination of watermelon crops. Global Change Biology 19, 3103-3110 https://doi.org/ $10.1111 / \mathrm{gcb} .12264$

McQuillan PB \& Hingston AB. 1999. Displacement of Tasmanian native megachilid bees by the recently introduced bumble bee Bombus terrestris (Linnaeus, 1758) (Hymenoptera: Apidae). Australian Journal of Zoology 47, 59-65.

Messina A. 2020. Rosaceae, in Phillip G. Kodela (ed.), Flora of Australia. Australian Biological Resources Study, Department of Agriculture, Water and the Environment: Canberra. Available from URL: https://profiles. ala.org.au/opus/foa/profile/Rosaceae [Date Accessed: 18 November 2020]

Michener CD. 1979. Biogeography of the bees. Annals of the Missouri Botanical Garden 66 (3), 277-347.

Miñarro M \& García D. 2018. Complementarity and redundancy in the functional niche of cider apple pollinators. Apidologie 49, 789-802.

Morandin LA \& Kremen C. 2013. Bee preference for native versus exotic plants in restored agricultural hedgerows. Restoration Ecology 21, $26-32$.

New TR. 2005. Invertebrate Conservation and Agricultural Ecosystems. Cambridge University Press, Cambridge, UK.

Nicholson CC, Ward KL, Williams NM et al. 2020. Mismatched outcomes for biodiversity and ecosystem services: testing the responses of crop pollinators and wild bee biodiversity to habitat enhancement. Ecology Letters 23 (2), 326-335.

PaDIL. 2020. Australian pollinators: Tasmania search. Available from: https://www.padil.gov.au/pollinators/search?sortType=ScientificName\& viewType $=$ Details \&pageSize $=10 \&$ queryText $1=$ Tasmania\&queryType 1 $=$ all Accessed 27/09/2020

Palmer-Jones T \& Clinch PG. 1966. Observations on the pollination of apple trees (Malus sylvestris Mill.) I. Variety Cox's Orange Pippin. New Zealand Journal of Agricultural Research 9 (2), 191-196.

Palmer-Jones T \& Clinch PG. 1967. Observations on the pollination of apple trees (Malus sylvestris Mill.) II. Varieties Granny Smith, Sturmer, Jonathan, and Cox's Orange Pippin. New Zealand Journal of Agricultural Research 10 (1), 143-149.

Palmer-Jones T \& Clinch PG. 1968. Observations on the pollination of apple trees (Malus sylvestris Mill.) III. Varieties Granny Smith, kidd's 
orange red, and golden delicious. New Zealand Journal of Agricultural Research 11 (1), 149-153.

Pardo A \& Borges PA. 2020. Worldwide importance of insect pollination in apple orchards: a review. Agriculture, Ecosystems \& Environment 293, 106839

Park M. 2012. Wild pollinators of Eastern apple orchards and how to conserve them (ed. TX Society). Cornell University

Park MG, Raguso RA, Losey JE \& Danforth BN. 2016. Per-visit pollinator performance and regional importance of wild Bombus and Andrena (Melandrena) compared to the managed honey bee in New York apple orchards. Apidologie 47, 145-160.

Paton DC. 1996. Overview of Feral and Managed Honey Bees in Australia: Distribution, Abundance, Extent of Interactions with Native Biota, Evidence of Impacts and Future Research. Australian Nature Conservation Agency, Canberra.

Pérez-Méndez N, Andersson GK, Requier F et al. 2020. The economic cost of losing native pollinator species for orchard production. Journal of Applied Ecology 57 (3), 599-608.

Pirk CW, Crewe RM \& Moritz RF. 2017. Risks and benefits of the biological interface between managed and wild bee pollinators. Functional Ecology 31, 47-55.

Pollinator Partnership Canada. n.d. Bee friendly farmer registration. Pollinator Partnership Canada, Canada.

Potts SG, Biesmeijer JC, Kremen C, Neumann P, Schweiger O \& Kunin WE. 2010. Global pollinator declines: trends, impacts and drivers. Trends in Ecology \& Evolution 25, 345-353.

Potts SG, Imperatriz-Fonseca V, Ngo HT et al. (2016) Safeguarding pollinators and their values to human well-being. Nature, 540 (7632), 220-229. https://doi.org/10.1038/nature20588

Prendergast KA. 2018. Nesting biology of Megachile ignita Smith, 1853 (Hymenoptera: Megachilidae) in artificial nesting blocks in urbanised southwestern Australia. Australian Entomologist 45, 139-148.

Prendergast K. 2020a. Beyond ecosystem services as justification for biodiversity conservation. Austral Ecology 45 (2), 141-143.

Prendergast K. 2020b. Native bees and their floral host associations in Tasmania apple orchards. Curtin University. Dataset. https://doi.org/10.25917/ 5 ee9d9bde413c

Prendergast K. 2020c. Native bees collected in Tasmania apple orchards October 2019. Curtin University. Dataset. https://doi.org/10.25917/arw1te90

Prendergast K. 2020d. Species of native bees in the urbanised region of the southwest Western Australian biodiversity hotspot. Dataset. https://oi. org/10.1002/ecs2.3076

Prendergast K, Menz MH, Bateman B \& Dixon K. 2020. The relative performance of sampling methods for native bees: an empirical test and review of the literature. Ecosphere 5, e03076. https://doi.org/10.1002/ ecs2.3076.

R Core Team. 2019. R: A Language and Environment for Statistical Computing, $\mathrm{R}$ version 3.6.2. $\mathrm{R}$ Foundation for Statistical Computing, Vienna, Austria.

Rader R, Howlett BG, Cunningham SA et al. 2009. Alternative pollinator taxa are equally efficient but not as effective as the honey bee in a mass flowering crop. Journal of Applied Ecology 46, 1080-1087.

Ramírez F \& Davenport TL. 2013. Apple pollination: a review. Scientia Horticulturae 162, 188-203.

Requier F, Odoux J-F, Tamic T et al. 2015. Honey bee diet in intensive farmland habitats reveals an unexpectedly high flower richness and a major role of weeds. Ecological Applications 25, 881-890.

Riessberger U \& Crailsheim K. 1997. Short-term effect of different weather conditions upon the behaviour of forager and nurse honey bees (Apis mellifera carnica Pollmann). Apidologie 28, 411-426.

Roulston TH \& Goodell K. 2011. The role of resources and risks in regulating wild bee populations. Annual Review of Entomology 56, 293-312.

Roulston TH, Smith SA \& Brewster AL. 2007. A comparison of pan trap and intensive net sampling techniques for documenting a bee (Hymenoptera: Apiformes) fauna. Journal of the Kansas Entomological Society $\mathbf{8 0}$, 179-181.

Russo L, Park M, Gibbs J \& Danforth B. 2015. The challenge of accurately documenting bee species richness in agroecosystems: bee diversity in eastern apple orchards. Ecology and Evolution 5, 3531-3540.
Salter M. 2002. Senate review of Australia's quarantine function: submission by Tasmania Apple \& Pear Growers Association Inc. Tasmania Apple \& Pear Growers Association Inc., Tasmania.

Saunders ME \& Luck GW. 2016. Combining costs and benefits of animal activities to assess net yield outcomes in apple orchards. PLOS ONE 11, e0158618.

Saunders ME \& Luck GW. 2018. Interaction effects between local flower richness and distance to natural woodland on pest and beneficial insects in apple orchards. Agricultural and Forest Entomology 20, 279-287.

Schwarz MP \& Blows MW. 1991. Kin association during nest founding in the bee Exoneura bicolor:active discrimination, philopatry and familiar landmarks. Psyche: A Journal of Entomology 98, 241-250.

Semmens T, Turner E \& Buttermore R. 1993. Bombus terrestris (L.) (Hymenoptera: Apidae) now established in Tasmania. Australian Journal of Entomology 32, 346-346.

Senapathi D, Biesmeijer JC, Breeze TD, Kleijn D, Potts SG \& Carvalheiro LG. 2015. Pollinator conservation - the difference between managing for pollination services and preserving pollinator diversity. Current Opinion in Insect Science 12, 93-101.

Settele J, Bishop J \& Potts SG. 2016. Climate change impacts on pollination. Nature Plants 2, 1-3.

Sheffield C, Ngo HT \& Azzu N. 2016. A manual on apple pollination. Pollination Services for Sustainable Agriculture. Food and Agriculture Organization of the United Nations (FAO), Rome.

Sheffield CS, Kevan PG, Pindar A \& Packer L. 2013. Bee (Hymenoptera: Apoidea) diversity within apple orchards and old fields in the Annapolis Valley, Nova Scotia, Canada. The Canadian Entomologist 145, 94-114.

Sheffield CS, Kevan PG, Westby SM \& Smith RF. 2008. Diversity of cavity-nesting bees (Hymenoptera: Apoidea) within apple orchards and wild habitats in the Annapolis Valley, Nova Scotia, Canada. The Canadian Entomologist 140, 235-249.

Silberbauer L. 1992. Founding patterns of Exoneura bicolor Smith in Cobboboonee State Forest, southwestern Victoria. Australian Zoologist 28, 67-73.

Simmons M, Wapstra H \& Wapstra A, eds. 2009. A Guide to Flowers \& Plants of Tasmania. New Holland Publishers, Chatswood, NSW.

Somerville DC. 1999. Pollination of apples by honey bees. In agnote, vol. DAI. NSW Agriculture, NSW.

Stephen WP \& Rao S. 2005. Unscented color traps for non-Apis bees (Hymenoptera: Apiformes). Journal of the Kansas Entomological Society 78, 373-380.

Stern R, Eisikowitch D \& Dag A. 2001. Sequential introduction of honey bee colonies and doubling their density increases cross-pollination, fruit-set and yield in 'Red Delicious' apple. The Journal of Horticultural Science and Biotechnology 76, 17-23.

Stout JC, Kells AR \& Goulson D. 2002. Pollination of the invasive exotic shrub Lupinus arboreus (Fabaceae) by introduced bees in Tasmania. Biological Conservation 106, 425-434.

Stout JC, Goulson D (2000) Bumble bees in Tasmania: their distribution and potential impact on Australian flora and fauna. Bee World, 81 (2), 80-86. https://doi.org/10.1080/0005772x.2000.11099475

Sugden EA \& Pyke GH. 1991. Effects of honey bees on colonies of Exoneura asimillima, an Australian native bee. Australian Journal of Ecology 16, 171-181.

Taki H, Murao R, Mitai K \& Yamaura Y. 2018. The species richness/abundance-area relationship of bees in an early successional tree plantation. Basic and Applied Ecology 26, 64-70.

Tangtorwongsakul P, Warrit N \& Gale GA. 2018. Effects of landscape cover and local habitat characteristics on visiting bees in tropical orchards. Agricultural and Forest Entomology 20, 28-40.

Thomson JD \& Goodell K. 2001. Pollen removal and deposition by honey bee and bumble bee visitors to apple and almond flowers. Journal of Applied Ecology 38, 1032-1044.

Tuell JK \& Isaacs R. 2010. Weather during bloom affects pollination and yield of highbush blueberry. Journal of Economic Entomology 103, 557-562.

Viana BF, da Encarnação Coutinho JG, Garibaldi LA, Gastagnino GLB, Gramacho KP \& da Silva FO. 2014. Stingless bees further improve apple pollination and production. Journal of Pollination Ecology 14, 261-269. 
Vicens N \& Bosch J. 2000. Pollinating efficacy of Osmia cornuta and Apis mellifera (Hymenoptera: Megachilidae, Apidae) on 'Red Delicious' apple. Environmental Entomology 29, 235-240.

Wagner DL, Ascher JS \& Bricker NK. 2014. A transmission right-of-way as habitat for wild bees (Hymenoptera: Apoidea: Anthophila) in Connecticut. Annals of the Entomological Society of America 107, 1110-1120.

Walker K. 1986. Revision of the Australian species of the genus Homalictus Cockerell (Hymenoptera: Halictidae). Memoirs of the Museum of Victoria 47, 105-200.

Walker K. 1995. Revision of the Australian native bee subgenus Lasioglossum (Chilalictus) (Hymenoptera: Halictidae). Memoirs of the Museum of Victoria 55, 1-423.

Wei S-G, Wang R, Smirle MJ \& Xu H-L. 2002. Release of Osmia excavata and Osmia jacoti (Hymenoptera: Megachilidae) for apple pollination. The Canadian Entomologist 134, 369-380.

Westphal C, Bommarco R, Carré G et al. 2008. Measuring bee diversity in different European habitats and biogeographical regions. Ecological Monographs 78, 653-671.

Williams NM, Cariveau D, Winfree R et al. 2011. Bees in disturbed habitats use, but do not prefer, alien plants. Basic and Applied Ecology 12, $332-341$.

Williams RR \& Brain P. 1985. Honey-bee activity when visiting flowers of the apple cultivars Cox's Orange Pippin and Golden Delicious. Journal of Horticultural Science 60, 25-28.
Wu P, Axmacher JC, Li X et al. 2019. Contrasting effects of natural shrubland and plantation forests on bee assemblages at neighboring apple orchards in Beijing, China. Biological Conservation 237, 456-462.

Accepted for publication 17 January 2021.

\section{SUPPORTING INFORMATION}

Additional supporting information may/can be found online in the supporting information tab for this article.

Table S1. Tasmanian apple orchards surveyed (A-D): geographic information, dates surveyed, management type, size and apple varieties.

Figure S1. Maximum daily temperature during each survey. 